\title{
Verdad geográfica de los humedales en $L a$ Araucana de Alonso de Ercilla
}

\author{
Juan José SANZ DONAIRE \\ Universidad Complutense de Madrid \\ jjsanzdo@ghis.ucm.es
}

\begin{abstract}
RESUMEN
La obra de Alonso de Ercilla ha sido objeto de análisis desde numerosos puntos de vista, especialmente los literarios, históricos e incluso patrióticos, pero apenas existen estudios de su realidad geográfica. A rellenar este hueco me propongo aportar algunos datos, con especial hincapié en el tratamiento que el autor realiza de los humedales o higrocoras.
\end{abstract}

Palabras clave: La Araucana, realidad geográfica, humedales.

Geographical truth of the wetlands in The Araucanian of Alonso de Ercilla

\begin{abstract}
Alonso de Ercilla's work has been an object of analysis from numerous points of view, specially literary, historical and even patriotic, but scarcely there exist studies of his geographical reality. To refilling this hollow I propose to contribute some information, with special support in the treatment that the author realizes of the wetlands or higrocoras.
\end{abstract}

Key words: The Araucanian, Geographical reality, Wetlands.

\section{Exposición sucinta de la vida del autor y el imbricado con su obra}

Muy esquemáticamente puede resumirse la cronología de la vida de Ercilla en el siguiente esbozo, en el que se imbrican las fechas de la publicación con los hechos de su vida:

- Nacimiento: 1533

- Viajes previos a la obra: Italia-Alemania

- Partida para América: 1555

Londres, Flandes (desde La Coruña)

- Campaña en Chile: 1557-58

- Regreso a la metrópoli: 1563

- Otros viajes

- $\quad 1^{a}$ Parte de La Araucana (1569). Cantos I a XV

- Más viajes

- $\quad 2^{\mathrm{a}}$ Parte de La Araucana (1578). Cantos XVI a XXIX 
- $\quad 3^{\mathrm{a}}$ Parte de La Araucana (1589). Cantos XXX a XXXVII

- Fallecimiento: 1594

De esta simple cronología se desprende la posible narración de los hechos acaecidos que hubieran vivido otros combatientes en situaciones semejantes. Dadas las altas dotes de observación y capacidad de comunicación de Alonso de Ercilla, éste podría haber incorporado experiencias de otros lugares, como las recientes campañas de Pavía, Parma y Plasencia, en las que desempeñaron un papel crucial los humedales... Así lo expresa Concha de Salamanca (1946) en su prólogo a la edición de la obra erciliana: "Y como siempre fue inclinado y amigo de inquirir y de saber, adquirió gran caudal de noticias acerca de todas las cosas..." (18). O también en: "Tenía, por otra parte, una espléndida retina captadora y una magnífica capacidad de recuerdo" (19). Estas afirmaciones tienen su apoyatura en la propia narración del poeta:

Yo, que fui siempre amigo e inclinado a inquirir y saber lo no sabido

(Canto XXXVI)

No obstante, teniendo en cuenta la tardía localización de este pasaje en la obra, bien podría tratarse de una justificación a posteriori que no de una exposición inicial de intenciones. Reitero que, como dice Isaías Lerner (2005), a la faceta de combatiente incorpora la de "descubridor y explorador de nuevas tierras" (15).

Serían pues sus contemporáneos los que le podrían haber llamado la atención sobre el modo de luchar en los humedales, independientemente de su capacidad de observación personal y directa. La misma comentarista anota las descripciones de paisajes de entre los que destaca las "aguas sombrías, aguas gredosas, totorales; charcas de lodo; grandes helechos..." (37) como ejemplo de los paisajes narrados por el poeta. A esta consideración añade entre paréntesis: "Hasta hace poco había en Cañete [la Araucanía, Chile] un árbol antiquísimo, a cuya sombra, según la tradición, Ercilla solía sentarse a escribir, contemplando el hermoso panorama que se extendía hacia la costa" (37-38).

Así pues, desde este instante y lugar, me propongo (de)mostrar la autenticidad narrativa del poeta en la descripción paisajística, con especial atención a las áreas encharcadas.

\section{Un problema casi resuelto: discutida historicidad de la obra \\ Carácter fidedigno de la narración: críticos a favor}

Pérez Blanco (1993) afirma que Ercilla en sus relatos, especialmente referidos a las complejas narraciones de los retratos demuestra maestría, pues para ello "se necesita dominio del idioma, ángel para la captación del espacio y, de un modo especial, la intuición repentina para hermanar espacio y verbo" (160). Éste constituye uno de los temas más abundantemente repetidos por el autor en la obra, 
así como una cualidad que la generalidad de la crítica alaba en la epopeya, una consideración que no todos los críticos de la obra admiten. No faltan, sin embargo quienes opinan que hay demasiada adherencia literaria que empaña el verismo de lo expuesto. Suele comentar el autor que se ciñe a la verdad, omitiendo las dudas:

Es relación sin corromper sacada

de la verdad, cortada a su medida;

no despreciéis el don, aunque tan pobre,

para que autoridad mi verso cobre. (Canto I)

En contar una cosa estoy dudoso

que soy de poner dudas enemigo (Canto IX)

Esta idea, no sólo la expresa el autor, sino que la hace suya Cedomil Goić (2005) con la literalidad de estas palabras referidas a las diferencias entre la obra de Ercilla y Cervantes al comienzo de su exposición: "uno épico y trágico y el otro realista y cómico" (651); así como en la conclusión (en el doble sentido de la palabra finalización y consecuencia, resultado o desenlace-): "Lo que es definidamente épico y trágico en Ercilla es novelesco y cómico en Cervantes" (661). Ya anteriormente, Francisco Martínez de la Rosa en su Apéndice sobre la poesía épica española (1827: 53-54) había expresado esta misma idea: "Así le sucedió que, en lugar de formar en su mente un plan completo y redondeado, fue escribiendo los sucesos que presenciaba, formando una relación más que un poema”. O más tarde (p. 54): "Ercilla tiene los defectos de un testigo presencial, y además los de una persona que toma sumo interés en una cosa á que ha concurrido: atiende á los pormenores más pequeños, teme omitir la cosa más leve, y no cuida el efecto general que debiera producir su obra". Este hecho, lejos de constituir una merma en la apreciación de la obra, la plaga de sentido, al menos desde la óptica que ahora utilizo.

Respecto de la verdad o verosimilitud, Morínigo (1983) se inclina hacia lo segundo, en sus propias palabras: "Como poeta que es, le resulta más fácil imaginar que ver. Cuenta lo que ve y canta lo que puede imaginar" (38). Más recientemente Álvarez Vilela (1995) también se hace eco de las palabras de Francisco Vidal Gormaz quien recorrió en 1871 el Sur chileno con La Araucana en la mano y reconoció las descripciones que el poeta había expuesto hacía ya tres siglos; a este homenaje a la geograficidad de la obra también se suma él, diciendo: "El relato de Ercilla sigue siendo de una veracidad histórica y de una precisión geográfica e incluso cronológica prácticamente irreprochables" (78). No obstante, tras esta rotunda afirmación, matizará sus aseveraciones en lo histórico precisando ciertos pormenores. Sostiene que mientras que la voluntad de oscurecer o ensombrecer la obra de D. García Hurtado de Mendoza en la epopeya le habría llevado a trastocar, en diversas ocasiones y ediciones, la realidad, debe admitirse la verosimilitud 
geográfica, en la medida en que no tiene necesidad de forzar el marco. Más recientemente Isaías Lerner (2005) vuelve sobre esta misma idea: "los elementos de la trama que componen la narración de la historia no son materia comprobable, pero las referencias geográficas y culturales de Chile y sus habitantes, los hechos bélicos, fueron tenidos por auténticos desde muy temprano" (19).

La verdad histórica ya había sido loada por otros autores: "Nada hay que neutralice ó atenúe la índole exclusivamente histórica de La Araucana, hasta el punto de no habérsele escapado á Ercilla ni aún la voz genérica de poema, aplicable á todo libro metrificado" (Ferrer del Río 1866: XLVII). O bien: "Con generoso cuidado hizo en verso heróico la relación verídica de las jornadas de los españoles á lo más apartado y escondido de la tierra, para que fuese más universal esta forma de escritura, cuanto lo es más la poesía que la historia" (XLIX). Y en la página LVI vuelve a calificar la obra erciliana de "verídica historia de tan pertinaz lucha"; y a la geografía dedica las siguientes palabras: "descriptos admirablemente los lugares" (LX y LXI). Parece, pues, que no sólo como materia docente de enseñanza, Geografía e Historia, también aquí aparecen unidas inseparablemente. En definitiva se trata de enmarcar los hechos acaecidos en las coordenadas espacio-temporales, algo en lo que está indefectiblemente inmerso todo mortal.

Entre otros, he aquí los comentarios, en el mismo sentido, de un estudioso autor extranjero: "Il nous parait d' ailleurs que c'est du côté de l'histoire et, à son défaut, de la poésie historique que Ercilla devait être poussé par son tempérament" o "Comme l'Araucana a, avant tout, un caractère tout historique, elle ne renferme pas et ne pouvait guère renfermer d'action proprement dite, c'est-à-dire un ensemble d'événements arbitrairement choisis et logiquement coordonnés en vue d'un effet ou d'un dénoûment voulu'(Ducamin, p. LIII). Esta ausencia de efecto o desenlace parece poner en entredicho la finalidad de la obra, aportándole a la misma mayores visos de autenticidad histórica. No deja de ser una afirmación demasiado tajante, pues en el poema existe, sin duda, intencionalidad, muy probablemente laudatoria, entre otras.

"Nous trouvons d'abord tout un premier chant consacré en entier à la géographie physique et politique de l'Arauco, et Voltaire y voyait de ce chef un morceau très intéressant et très neuf" (LXV). "Il y a unanimité chez les critiques pour louer le talent descriptif d'Ercilla" aunque, agrega que "Ticknor fait une réserve pour les descriptions de la nature où il le trouve inférieur" (ambas citas en la página LXVI y LVII). Se refiere a las descripciones de personajes, auténticos protagonistas de la obra, con un peso muy superior en versos a las descripciones del entorno. Más adelante, admite que ofrece una "impression exacte des épaisseurs impénétrables de leurs forêts vierges, de leurs abîmes et de leurs marécages infranchissables" (ibíd.). "Il est encore presque de notre temps pour le souci du détail pittoresque et précis et par le goût de l'expression propre et technique" (p. LXIII). 


\section{La estima del adversario araucano}

Esta misma idea, lejos del tema que ahora estrictamente nos preocupa, también se plasma en la tantas veces loada comprensión, cuando no admiración del enemigo, no sólo en los primeros compases de su obra sino bien al final de la misma.

pues no es el vencedor más estimado

de aquello en que el vencido es reputado. (Canto I)

que el valor más se muestra y se parece

cuando la fuerza de contrarios crece (Canto XXXV)

Como en los Romances de frontera o en el Abencerraje, se hace gala de un enemigo poderoso, del que se cantan grandes alabanzas sin escrúpulo alguno:

y puso al español en tal aprieto

cual presto se verá en la carta mía (Canto I)

que es la necesidad grande inventora,

y el trabajo solícito en las cosas,

maestro de invenciones ingeniosas. (Canto I)

\section{La consideración divina de los conquistadores}

Prueba de la consideración de los españoles entre los indígenas son las palabras de Ercilla: de divina procedencia los jinetes, dominadores de los rayos y truenos (tiros de pólvora)
Ayudó mucho el inorante engaño
de ver en animales corregidos
hombres que por milagro y caso estraño
de la región celeste eran venidos;
y del súbito estruendo y grave daño
de los tiros de pólvora sentidos,
como a inmortales dioses los temían
que con ardientes rayos combatían. (Canto I)

Todavía idea puesta en boca de un araucano al final de la obra: "arrojan rayos con estruendo horrible" (Canto XXXIV).

Sin embargo en el canto II se desdice de la condición divina que los indígenas habían concedido a sus adversarios:

Por dioses, como dije, eran tenidos

de los indios los nuestros; pero olieron

que de mujer y hombre eran nacidos, 
y todas sus flaquezas entendieron. (Canto II)

Y, con el transcurrir del tiempo, realizadas bastantes batallas, las cosas cambian en la consideración de los caciques mapuches respecto de los españoles:

diciendo: “A mí la España no me espanta

y no quiero por hombre ser tenido

si solo no arruino a los cristianos.

Ahora sean divinos, ahora humanos" (Canto VIII)

Y el caudillo Lautaro afirma, para terminar con la divinidad de sus adversarios, que éstos deben su superioridad no a una condición esencial sino a los ardides, ingenio, aprovechamiento de las circunstancias, amén de al modo de proceder:

con españoles siempre he militado, entiendo sus astucias e invenciones, el modo, el arte, el tiempo y ocasiones. (Canto IX)

\section{Un problema añadido: la geograficidad}

William Mejías-López (1992) escribe: "Ercilla fue sin duda el que mejor supo aprovechar las fuentes literarias y las experiencias propias para escribir un poema" (279). También agrega: "Estudiadas detenidamente, las alusiones geográficas nos llevan a enmarcar su [del mago Fitón] morada en la zona araucana de Chile en cuyos límites predomina un clima lluvioso con una vegetación rica y variada, cubierta de bosques, enredaderas y arbustos. La topografía, la flora y la fauna registradas anteriormente reafirman su realismo. Se menciona a Rauco [río chileno], al cedro del Líbano, que aunque no se especifica, conjeturamos que se trata del Libocedrus chilensis, muy común en la región, y una mansa corcilla cerca del río, mamífero que habita en Europa y en algunos bosques de Chile, Argentina, Brasil y Paraguay. Complementa el escenario una selva densa poblada de matorrales y árboles cerrados" (291 y 292).

cuando acaso pasares la cañada

por donde corre Rauco más ceñido

verás al pie de un libano a la orilla

una mansa y doméstica corcilla. (Canto XVII)

De Lucrecio Pérez Blanco (1993) procede esta cita: "Descripción gráfica, real, hipnotizadora del lector, que se ve así envuelto de una manera absoluta por la acción, olvidándose de lo que le rodea. Momentos hay en que la descripción es suave y tranquila, donde la naturaleza se ilumina como pacífica y serena característica del paisaje renacentista" (133). "Al lado de estas descripciones propiamente geográficas con las que el poeta fija la situación de un país o región, 
nos encontramos con otras con las que se describen lugares pequeños, pasos, lo más, valles, pueblos, lugares fortificados, selvas, etc., etc. En unos y en otros, Ercilla siempre se muestra exacto y minucioso, no dejando escapar el más mínimo detalle" (134). "Ercilla es minucioso y preciso al máximo en otro tipo de descripciones" (140).

La única referencia completa a la geografía del poema de La Araucana fue escrita por González de Mendoza (1947) y en ella se plantea más el ajuste tiempoespacio de la narración, que la auténtica descripción geográfica de la obra. Ésta tiene principalmente dos expresiones: la Geografía Descriptiva del Mundo, y la del territorio chileno.

\section{La agregada Geografía del Mundo}

Hay cantos en los que se introducen descripciones o relatos ajenos a la trama específica de La Araucana: son los dedicados al mago Fitón (Cantos XVIII, XXIII, XXIV, XXVI y XXVII), siendo el último ejemplo de lo que no es sino una geografía en sentido estricto, una descripción de la Tierra hasta entonces conocida, o la historia de la desdichada Glaura (Canto XXVIII), como, más tarde, la de Lauca (Canto XXXII) que da pie a la exposición de Dido (Cantos XXXII y XXXIII), que el propio autor califica de digresiones o, al decir de la época, "diversiones" ("en larga digresión me he divertido" tras el episodio del mago; "pensando también con divertirme" antes de la de Dido).

En el Canto XXVII hay varias menciones genéricas a lagunas, más sin ninguna especificación, al hacer una prolija descripción geográfica del Mundo -valgan las redundancias etimológicas de lo que significa literalmente geografía-, descripción que pone el autor en boca del mago Fitón:

lo que hay del norte al sur, del leste al oeste,

y cuanto ciñe el mar y el aire abraza,

ríos, montes, lagunas, mares, tierras

famosas por natura y por las guerras ${ }^{1}$. (Canto XXVII)

Vees la fragosa sierra de Capira,

Cartagena y las tierras que se estienden

de Santa Marta y cabo de la Vela

hasta el lago y ciudad de Venezuela; (Canto XXVII)

Mira el solsticio y trópico pasado,

\footnotetext{
${ }^{1}$ No es de extrañar que en cierta ocasión se haya declarado que la Geografía, en clave marxista, sirva primordialmente para hacer la guerra. Cfr: Yves Lacoste (1976): La géographie, ça sert d'abord à faire la guerre. Máspero. París. Hay recientes ediciones aumentadas y renovadas (2012 y 2014) en Éditions La Découverte.
} 
del austral Capricornio las regiones, de varias gentes bárbaras estrañas los ríos, lagunas, valles y montañas. (Canto XXVII)

La falta de concreción se interrumpe, sin embargo, cuando se refiere a las "bocas" del Nilo o a la Laguna de Maracaibo venezolana:

Destos peñascos ásperos pendientes, llamados hoy el monte de la Luna, nacen del Nilo las famosas fuentes, y dellos ríos sin nombre y fama alguna, que aunque tuercen y apartan sus corrientes se vienen a juntar a una laguna tan grande, que sus senos y laderas baten de tres provincias las riberas:

a Gogia y Beguemedros al oriente, y a Dambaya al poniente; del cual lado hay islas donde habita varia gente y todo el ancho círculo es poblado. De aquí el famoso Nilo mansamente nace, y después más grande y reforzado parte a Gogia de Amara y va tendido sin ser de las riberas restringido (Canto XXVII)

Es llamativo que en una obra como La Araucana se inserte todo un tratado de Geografía Universal. Por ello Morínigo (1983) ha aventurado que sea éste un añadido a la obra original, en el que el autor deseaba ofrecer la máxima gloria al César, cantando el ámbito terráqueo del Imperio en el que no se ponía el sol: "La única razón plausible es que decidió seguir ampliándola [su obra] para dar cabida a algo de que el poema carecía y que dadas las circunstancias del tiempo era una falta notable en una obra histórico-poética sobre los hechos coetáneos: la glorificación de su pueblo y la de su monarca como factor eficiente de los triunfos de la nación" (51).

\section{La descripción de Chile}

Valga destacar la exactitud geográfica, en su contexto histórico

Por cierto que, al parecer, o, mejor dicho, a tenor de la delimitación en el canto I, el territorio araucano más indómito está bien localizado a $36^{\circ} \mathrm{S}$. No obstante en su totalidad es de gran extensión, dado que llega desde los $27^{\circ} \mathrm{S}$ hasta los confines explorados por la travesía al Pacífico.

Pues en este distrito demarcado, por donde su grandeza es manifiesta, 
está a treinta y seis grados el Estado que tanta sangre ajena y propia cuesta (Canto I)

La descripción de su "cinta" chilena queda bien expuesta del siguiente modo: larga, desde los $27^{\circ} \mathrm{S}$ hasta la comunicación de los dos océanos:

Es Chile norte sur de gran longura, costa del nuevo mar, del Sur llamado, tendrá del leste a oeste de angostura cien millas, por lo más ancho tomado; bajo el polo Antártico en altura de veinte y siete grados, prolongado hasta do el mar Océano y chileno mezclan sus aguas por angosto seno. (Canto I)

aunque más tarde se especifique que el paso entre las masas marinas se realiza a través del estrecho de Magallanes:

$\mathrm{Y}$ estos dos anchos mares, que pretenden, pasando de sus términos, juntarse, baten las rocas, y sus olas tienden, más esles impedido el allegarse; por esta parte al fin tierra hienden y pueden por aquí comunicarse. Magallanes, Señor, fue el primer hombre que, abriendo este camino, le dio nombre. (Canto I)

Para más información sobre la largura del territorio, añade la longitud de la Sierra, los Andes chilenos:

a la banda de leste va una sierra que el mismo rumbo a mil leguas camina (Canto I)

Debe tenerse en cuenta que la legua castellana era, en el siglo XVI, de una distancia de $5.572 \mathrm{~m}$, si bien la marina, en esa época, poseía una equivalencia de 17,5 al grado de meridiano (luego $6.349 \mathrm{~m}$ ). En cualquiera de los dos casos la estimación del cordón montañoso está ligeramente abultada, ¿por mor de la necesidad métrica del verso?, ¿por atracción de los números redondos? Pero en cualquier circunstancia es en su centro donde más belicosa se presenta la población:

en medio es donde el punto de la guerra por uso y ejercicio más se afina. (Canto I) 
De las siete primeras ciudades fundadas por Valdivia, una posee el nombre del Lago. Queda así patente la importancia del agua y de los humedales del centro-sur chileno desde el mismo inicio de la colonización ${ }^{2}$.

siete ciudades prósperas fundaron:

Coquimbo, Penco, Angol y Santiago,

la Imperial, Villarrica, y la del Lago. (Canto I)

Es interesante que de las siete, aparte de Coquimbo (junto a La Serena) y Santiago, las restantes cinco se ubiquen en La Araucanía: Penco en la región de

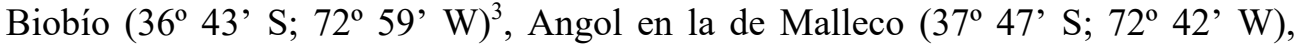
Imperial en la de Cautín, identificada con la Carahue de hoy, a $20 \mathrm{~km}$ de la actual Nueva Imperial ( $38^{\circ} 54^{\prime} \mathrm{S}$; $72^{\circ} 57^{\prime} \mathrm{W}$ ), y Villarrica en su lago homónimo (39 $16^{\circ}$ S; $71^{\circ} 19^{\prime} \mathrm{W}$ ), aunque suele darse a Jerónimo de Alderete por su fundador en 1552 , y se desconoce con seguridad la localización de la del Lago.

Por otra parte en el texto se habla de otras poblaciones como Valdivia (Canto VIII), La Serena (Canto VIII), La Concepción (Canto II, VII, XII, XV, XVI)...

En ciertos ámbitos se ha destacado, sin embargo, "una sensibilidad extraordinaria, la de Ercilla, frente al paisaje" (Giuseppe Bellini 2006: 4). También en la obra de Vega de Febles (1991) se define al poeta como conciso y realista, autor de "gráficas descripciones" (77 y 91).

Por cierto que, desde la perspectiva de poesía épica, se ha cargado peyorativamente sobre las buenas descripciones geográficas del autor. Así Francisco Martínez de la Rosa (1827) en su Apéndice de la poesía épica reza textualmente: "y cierto se le debe condenar por haber empleado largo espacio en hacer la descripción geográfica de la tierra" [de Chile] (55). Y ello aunque más adelante loe la capacidad de descripción: "la misma maestría [que la expresada en la idea del pueblo] ostenta Ercilla en todo género de descripciones" (70). Por lo que se ve, lo que importuna al comentarista no es tanto las descripciones "literarias", de reconocida cabida en la narrativa, sino las espaciales o geognósticas, por utilizar vocablo de la época del apostillero.

${ }^{2}$ Por colonización quiero expresar aquí lo que se deriva del mismo sentido etimológico de la palabra, emanada de los vocablos latinos colo, colonus, colonia: cultivar, entrada y asentamiento de colonos, de habitantes. Por ende también tiene el sentido de venerar, honrar, adorar, por el preeminente puesto que ostenta la tierra en la concepción del territorio. Es una desgracia que hoy se haga coincidir el vocablo más con una idea de "neocolonización" -puramente económica y hasta explotadora-, que con el significado original.

${ }^{3}$ En el preámbulo del Canto IX se afirma: "Les vino nueva que los españoles estaban en el asiento de Penco reedificando la ciudad de La Concepción”, por lo que son la misma o inmediatas. 
¡Qué buena explicación de la camanchaca costera, ligada al enfriamiento de la atmósfera en sus capas más bajas de la troposfera cuyo origen está en la corriente fría de Humboldt o del Perú, y del "invierno boliviano", así como del modo de producirse las crecidas en el deshielo estival andino, cuando los serenísimos cielos lo permiten! De nuevo el relato versado del poeta permite en apretada síntesis la descripción de los fenómenos observados, toda vez que el autor ya se ha incorporado a la acción y expone sus propias vivencias.
¿Qué hay en Pirú, no es caso soberano tanta mudanza en tres leguas de tierra, que cuando es en los llanos el verano, los montes el lluvioso invierno cierra? Y cuando espesa niebla cubre el llano en descubierto hiere el sol la sierra y por esta razón van más crecientes en el verano abajo las vertientes. (Canto XIII)

En la descripción de Chile faltaba, sin embargo, la mención de dónde comienza el auténtico Chile, cosa que hace el poeta al mencionar la ayuda que por vía marítima llega desde la Ciudad de Los Reyes (Lima, a través de su puerto Callao), expresado con estas palabras:
a Chaule a la siniestra, y arribaron
en Arica, y después difícilmente
vimos a Copiapó, valle primero
del distrito de Chile verdadero. (Canto XV)

Parece destilar esta afirmación el sentimiento de que por el Paso de San Francisco hacia Copiapó había entrado el descubridor Almagro en Chile, razón de gran peso para hacer a este valle y población límite septentrional del Chile de entonces.

También se refleja la naturaleza de los vientos, encerrados - cuando hay calmaen cavernas subterráneas, para ahuyentarse en ciertos momentos, siendo además interpretados los temblores de tierra tan frecuentes en esta parte del mundo como una de sus manifestaciones.
No con esto su furia corregida, viéndose en sus cavernas apremiados, buscan con gran estruendo la salida por los huecos y cóncavos cerrados; $\mathrm{y}$ así la firme tierra removida tiembla, y hay terremotos tan usados, derribando en los pueblos y montañas 
hombres, ganados, casas y cabañas. (Canto XV)

En este final del primer libro también agrega acertadas descripciones comparativas respecto del hemisferio Norte:

Menguan allí las aguas, crece el día al revés de la Europa, porque es cuando

el sol del equinocio se desvía

y al Capricornio más se va acercando.

Pues desde allí las naves que a porfía corren, al mar y al Austro contrastando, de Bóreas ayudadas luego fueron y en el puerto coquímbico surgieron. (Canto XV)

\section{La aportación actual: los humedales}

Conozco sólo un antecedente explícito aunque muy somero en Fernando Alegría (1954) quien cita descripciones paisajísticas muy propias de Chile, en especial las dedicadas a pantanos y ríos: "Podría citar descripciones de los pantanos (XXII. 237) en la actual región de Curicó o del rio Itata y la Cordillera (XII. 240) o del Archipiélago de Chiloé (XXXVI) o esa tempestad que concluye la Primera Parte y en la cual el mar y el viento del sur de Chile se hacen presentes con toda su violencia" (47).

Sin embargo Ercilla ofrece máxima precisión en la narrativa de las actuaciones en las higrocoras, destacando ciertos aspectos que luego desglosaré:

- Carácter defensivo de los trampales frente a la caballería: su uso entre los amerindios

- Construcción de un fuerte en medio de un pantano: la utilización de los conquistadores

- Emboscada entre los carrizales: ocultamiento del enemigo

- Características térmicas, muy bien observadas

- El humedal como locus amøenus

- Carácter defensivo de los trampales frente a la caballería: su uso entre los amerindios

La primera ocasión en la que se cita algo referido a los humedales es con motivo de los lugares de refugio durante las contiendas. Son, pues, éstos adarve de retirada, máxime por cuanto que protegen de la pavorosa caballería, sin duda el arma más temida por los araucanos, no ya por una concepción sobrenatural de jinete soldado al caballo en pieza única, sino por la celeridad de desplazamiento y masa en movimiento, contra la que es difícil guarecerse a no ser sacando ventaja del terreno. 
De pantanos procuran guarnecerse por el daño y temor de los caballos, donde suelen a veces acogerse si vienen a suceder desbaratallos; allí pueden seguros rehacerse ofenden sin que puedan enojallos, que el falso sitio y gran inconveniente impide la llegada a nuestra gente. (Canto I)

No es baladí que se trate las higrocoras de "falso sitio", epíteto que se repetirá en otras ocasiones, o de "gran inconveniente", pues se tiene una completa apreciación del poder retardador de la avanzada militar. Más adelante se volverá sobre esta idea.

Esta consideración no ha sido pasada por alto en los estudiosos del autor, en su literalidad. Así, Ferrer del Río (1866: XVI) recoge: "tras de fiera lucha en un pantano, donde los indios se acogieron por miedo á los caballos".

"Luchábase en aquel terreno pantanoso, perfectamente elegido por los indios para librarse de los caballos, a pie, metidos en el cieno, a veces hasta la cintura" (Medina 1916: 53). También lo debe recoger la epopeya....

Por contra, respecto de la dificultad que tiene para los caballos y hombres la lucha en los pantanos, las contiendas se libran en "prados", como admite en el Canto II:

cubre la roja sangre todo el prado, tornándole de verde colorado. (Canto II)

Una vez más es el paso retrasado por las ciénagas:

en fin a poco trecho los alcanzan, que un paso cenagoso los detiene. (Canto III)

Otra vez se aprecia el valor estratégico de las ciénagas, pantanos y lagunas que tanto caracterizan a la Araucanía, que son los aliados del terreno de los indígenas.

La vitoria tenemos en las manos y pasos en la tierra mil seguros de ciénagas, lagunas y pantanos, espesos montes, ásperos y duros; mejor pelean aquí los araucanos, españoles mejor dentro en sus muros; cualquier hombre en su casa acometido es más sabio, más fuerte y atrevido. (Canto III) 
Los araucanos sacan provecho del terreno que les es propio; no así los hispanos. La ventaja de la caballería española se desmorona en las áreas anegadizas ante la superioridad numérica y de aprovechamiento del terreno que tienen los nativos.

$\mathrm{Y}$ es de suponer que, a falta de una descripción más prolija, la mención a un valle estrechado por un lago sea debida a la acción glaciárica. A este fin véase la siguiente mención:
Estréchase el camino de Elicura por la pequeña falda de una sierra; la causa y la razón desta angostura es un lago que el valle abajo cierra. (Canto IV)

Los humedales son habituales en la áreas ocupadas por los araucanos, a tenor de las copiosas lluvias, a veces especialmente violentas, hasta el punto de calificarlas de auténticas tempestades, como se narra en el Canto IX o se encuentra en el prolegómeno del Canto XV donde se narra "la grande tormenta [...] entre el río Maule y el puerto de La Concepción". Puede afirmarse que este chubasco ocurre durante el verano por mor de que es el tiempo en que "la aguda chicharra se entonaba con un desapacible contrapunto":

Cuando el campo de allí quería mudarse, que ya la trompa a caminar tocaba, súbito comenzó el aire a turbarse, y de prodigios tristes se espesaba nubes con nubes vienen a cerrarse, turbulento rumor se levantaba, que con airados ímpetus violentos mostraban su furor los cuatro vientos.

Agua recia, granizo, piedra espesa las intrincadas nubes despedían; rayos, truenos, relámpagos apriesa rompen los cielos y la tierra abrían; hacen los vientos ásperos represa que en su entera violencia competían; cuanto topa arrebata el torbellino, alzándolo en furioso remolino.

Un miedo igual a todos atormenta; no hay corazón, no hay ánimo así entero que en tanta confusión, furia y tormenta no temblase, aunque más fuese de acero; en esto Eponamón se les presenta en forma de un dragón horrible y fiero 
con enroscada cola envuelta en fuego y en ronca y torpe voz les habló luego diciéndoles que apriesa caminasen sobre el pueblo español amedrentado, que por cualquiera banda que llegasen con gran facilidad sería tomado, y que al cuchillo y fuego la entregasen sin dejar hombre a vida y muro alzado. Esto dicho, que todos lo entendieron, en humo se deshizo y no lo vieron.
Al punto los confusos elementos fueron sus movimientos aplacando, y los desenfrenados cuatro vientos se van a sus cavernas retirando; las nubes se retraen a sus asientos el cielo y claro sol desocupando; sólo el miedo en el pecho más osado no dejó su lugar desocupado.
La tempestad cesó y el raso cielo vistió el húmido campo de alegría, cuando con claro y presuroso vuelo en una nube una mujer venía cubierta de un hermoso y limpio velo con tanto resplandor, que al mediodía la claridad del sol delante della es la que cerca dél tiene una estrella. (Canto IX)

Pero a raíz de una aparición se produce el extraño caso, al que el autor no exime del carácter de milagroso, de que el cielo "se cierre" durante dos años, señoreando una gran sequía, con las consiguientes secuelas en la habitación humana:
que por esta visión hubo en dos años
hambres, dolencias, muertes y otros daños.
Que la mar reprimiendo sus vapores, faltó la agua y vertientes de la sierra, talando el sol en tierna edad las flores, ayudado del fuego de la guerra.
Como creció la seca y las calores por falta de humidad la árida tierra rompió blanco y alzóse con los frutos, dejando de acudir con sus tributos. (Canto IX) 
Los españoles huyen: "por sierra, monte, llano y por cañada" (Canto IX), con el fin de no dejar tierra sin nombrar. Esta enumeración bien puede establecer la diferencia entre las montañas altas -aserradas, objeto de la acción de las inclemencias atmosféricas de la meteorización o intemperismo, sin descuidar la ayuda de las pendientes torrenteras y los glaciares, y probablemente por ello desprovistas de vegetación-, el monte como formación biogeográfica, el llano y la cañada, que lejos de tener un sentido estrictamente pastoril o viario bien podría referirse a lo que etimológicamente significa: "lugar de cañas". Probablemente la razón estribe en que el ganado transhumante utiliza las tierras baldías, no las agrícolas ni los pastos que pertenecen a otros propietarios. Así sólo les quedan disponibles los terrenos baldíos, infértiles, de las riberas de los ríos, los humedales de las cintas que acompañan a los ríos. De este modo se establecería en el verso una correspondencia entre el primer y tercer términos (ambos geomorfológicos) y el segundo y cuarto, con connotaciones de vegetación. En tal caso es de esperar que se trate de la vegetación ripícola de algún río o de la ribera de un lago -que podría llegar a extenderse tanto que llegase a colmar la depresión otrora ocupada por un aguazal. Las áreas a las que hace referencia el autor están totalmente salpicadas, incluso en la actualidad, de estas hondonadas húmedas a modo de navas.

No se me escapa que hoy en día se emplea en numerosos lugares de la América de habla española el término "cañada" en el sentido de "terreno bajo entre lo más, cuchillas o sierras, bañado de agua a trechos o en toda su extensión, y con vegetación propia de tierras húmedas" (diccionario de la RAE), pero, en su derivación del latín canna, es más bien un canal, "espacio de tierra entre dos alturas poco distantes entre sí" (primera acepción de la RAE). No descarto, sin embargo que la acepción actual hispanoamericana derive de la literalidad como expongo más arriba, idea que recogen Corominas y Pascual (1980: vol. I, 821).

Al propio tiempo unos versos más tarde el autor repite otra vez la misma construcción al referirse a todo el espacio: "por sierras, valles, montes, por ejidos" (Canto IX).

En apoyo de la interpretación que se hiciera con anterioridad también aquí se contraponen los términos, geomorfológicos, primero y segundo, a los tercero y cuarto, biogeográficos o de ocupación del suelo (vegetación natural y utilización comunal del terreno). Indudablemente también ha debido influir en la redacción la necesidad de rimar, en la primera cita, "jornada "con "cañada" así como ahora "esparcidos" con "ejidos".

Efectivamente, siendo de máxima importancia en el verso la rima, más adelante vuelve a encontrarse otro pasaje similar: "los valles, montes, llanos y riberas" (Canto X).

En esta ocasión se han cambiado los vocablos de lugar, no afectando al ritmo dentro de la estrofa, para hacer coincidir la rima consonante con la antecedente palabra "forasteras". Pero, una vez más, se agrupan los vocablos por parejas: 
primero con tercero son de significado topográfico, frente al segundo y cuarto, vegetacional.

Ahondando en esta idea también está la obra de Medina (1916) que afirma que cierta expresión "no es simulada, hija de las necesidades de la rima o de los adornos del lenguaje, pues existía en la conciencia del poeta" (174). Una vez más el verismo se impone a la métrica epopéyica.

Aunque comentando otras situaciones, Pérez Blanco (1993) afirma, ahondando en lo que llevo dicho: "todo en simetría herreriana para lograr el cuadro vivo y luminoso con lo que la pluma toma ventaja sobre el pincel" (159, el subrayado es mío). Con posterioridad Isaías Lerner (2005) ha vuelto a llamar la atención sobre la "acumulación de epítetos, estructuras sintácticas paralelísticas, comparaciones de la tradición clásica" (38), o sobre las serie generalmente trimebres aunque "Ercilla extiende hiperbólicamente a series cuatrimembres" (42).

En alguna ocasión se hace eco el poeta de las comparaciones de los ámbitos húmedos para referirse al modo en que se atacan unos protagonistas a otros. Queda sin embargo en la conjetura que la alegoría se haya hecho teniendo en cuenta el ambiente real que se veía en las inmediaciones del campo de batalla o de ejercicio. Personalmente me inclino por esta posibilidad.

Y cual halcón que en la húmida ribera

ve la garza de lejos blanqueando (Canto XI)

De la veracidad del relato hace gala, por ejemplo, el hecho de las noticias que el autor da del río Claro (Canto XI), cuando afirma:

Dióse tal priesa a andar que presto vino

a la corva ribera del río Claro, que vuelve atrás en círculo gran trecho, después hasta la mar corre derecho.(Canto XI)

Sabemos que existen bastantes ríos denominados Claro en Chile, pero los más conocidos son los que se dan -hasta 3 del mismo nombre- como tributarios del Maule, por cierto de significado "lluvioso" en mapudungún. En efecto el Maule, que desemboca al mar en Constitución, no posee esta curva, salvo que se le agregue el afluente Loncomilla, con el trazado abiertamente giratorio, pues nacido en la cordillera de la costa, vierte aguas hacia el Oriente, para girar luego al Pacífico.

No descarto que se trate del río más septentrional, el Mataquito, procedente de Curicó, que posee en las inmediaciones de su salida al mar una amplia curva, a fin de salvar la flecha de arena S-N que cierra un antiguo estuario. Esta flecha es provocada por la aportación sólida del Maule y afecta tanto a la margen derecha de la desembocadura de éste, como a los vecinos septentrionales Huechullami y 
Mataquito. El "Mataquito" es también explícitamente citado en el Canto XII como localizador de un camino recorrido.

En cualquiera de las dos posibilidades, nos hallamos en el confín de lo que los españoles del momento consideraban los límites septentrionales del Estado de Arauco.

Otra vez se plantea el mismo asunto. Los trampales de los lugares llanos, al pie de las montañas, auténticos pantanos, cuando no claros lagos en los que el agua sobrenada al suelo, son lugares de dificultad para usar el arma de caballería, que siempre se ha caracterizado por su capacidad de movimiento y ha hecho gala de la misma, pero que en estos terrenos se ve restringida en su maniobra.

En tan pocas palabras es posible una tan certera descripción del terreno, "tierra honda, floja, anegadiza, hueca, falsa, esponjada y movediza”. Así se explican los numerosos nombres con los que se la menciona: trampal, tremedal ("quaker", "Queckland"), aguazal, "bog" en atención a su carácter flojo, arqueable (emparentado con el "bow" inglés o el alemán "Bogen"), nombre que detenta en la hiperhúmeda Irlanda, etc.

Al propio tiempo se menta la excavación de zanjas para desaguar el excedente hídrico del suelo, a efectos de evitar el encharcamiento.

\author{
Que aquel sitio cercado de montaña, \\ que es en un bajo y recogido llano, \\ de acequias copiosísimas se baña \\ por zanjas con industria hechas a mano. \\ Rotas al nacimiento, la campaña \\ se hace en breve un lago y gran pantano; \\ la tierra es honda, floja, anegadiza, \\ hueca, falsa, esponjada y movediza. \\ Quedaran, si las zanjas se rompieran, \\ en agua aquellos campos empapados; \\ moverse los caballos no pudieran \\ en pegajosos lodos atascados, \\ adonde, si aguardaran, los cogieran \\ como en liga a los pájaros cebados; \\ que ya Lautaro, con despacho presto, \\ había en ejecución el ardid puesto. (Canto XII)
}

Lo relatado hasta aquí no procede de experiencia propia, sino que está recogido de otros actores. Así se afirma en el subsiguiente párrafo, lo que no desdice que sea fidedigno y fruto de los conocimientos que ha ido adquiriendo:

Hasta aquí lo que en suma he referido yo no estuve, Señor, presente a ello 
y así, de sospechoso, no he querido

de parciales intérpretes sabello;

de ambas las mismás partes lo he aprendido,

y pongo justamente sólo aquello

en que todos concuerdan y confieren

$y$ en lo que en general menos difieren.

Pues que en autoridad de lo que digo

vemos que hay tanta sangre derramada,

prosiguiendo adelante, yo me obligo

que irá la historia más autorizada;

podré ya discurrir como testigo

que fui presente a toda la jornada,

sin cegarme pasión, de la cual huyo,

ni quitar a ninguno lo que es suyo. (Canto XII)

\section{El humedal como "locus amænus"}

Cuando se cita otros lugares, adecuados, se tiene en cuenta el locus amonus, como en el caso que a continuación se cita con ocasión de los conciliábulos de los "caciques":

Hácese este concilio en un gracioso asiento de mil florestas escogido, donde se muestra el campo más hermoso de infinidad de flores guarnecido; allí de un viento fresco y amoroso los árboles se mueven con ruido, cruzando muchas veces por el prado un claro arroyo limpio y sosegado, do una fresca y altísima alameda por orden y artificio tienen puesta en torno de la plaza y ancha rueda, capaz de cualquier junta y grande fiesta, que convida a descanso, y al sol veda la entrada y paso en la enojosa siesta; allí se oye la dulce melodía del canto de las aves y armonía. (Canto I)

Y frente a lo que afirman notables estudiosos de la obra como Guillermo Araya, que cita expresamente "la descripción de los tópicos del paisaje" (10), he podido mostrar numerosos ejemplos -entre ellos el anterior- en los que no se habla de descripciones estereotipadas, sino de finas apreciaciones bien pegadas a la realidad. Por ello pienso que no debe continuar repitiéndose la apreciación de locus amønus como tópico de los humedales sino dar a conocer la importancia documental de las descripciones territoriales. A pesar de que esta consideración de tópico de gran 
raigambre renacentista tiene sus raíces hundidas en la Antigüedad clásica, hay interpretaciones de la Ilíada (Sanz Donaire 2001: 147 y 157) o en Estrabón (Sanz Donaire 1999) en las que se apuesta con preferencia sobre la literalidad y verismo higrocórico. Defensora de la postura contraria en La Araucana es Rosa PerelmuterPérez (1986), que comenta la "falta de exactitud descriptiva también podría responder al extendido intervalo entre acontecimiento y escritura" (130) o a falta de interés por la "cualidades estéticas" (131). Y remacha: "Poco hay en estos paisajes, indudablemente, que no remita a Chile; si acaso remiten a un Chile idealizado, cuyas perfecciones se deben no a la observación directa de Ercilla sino a recuerdos literarios" (132 y 133). Y enumera los típicos tópicos de los loci amœeni: árbol (uno o varios), prado, fuente o arroyo, canto de aves, flores, soplo de la brisa, un cuadro pastoril, "aunque sin pastores" (145), emparentado en el concepto de Paraíso terrenal bíblico, Edén, Campos Elíseos, Edad de Oro primigenia, etc. Existe, sin embargo, una compatibilidad entre esas apreciaciones y las que yo defiendo, pues los loci amoeni se exponen con preferencia en la descripción inicial y en el contexto del archipiélago de Chiloé. Pero lo más autobiográfico sería la narración del área central, la Araucanía propiamente dicha, la fidedigna exposición bélica.

Aún más y por ello, al volver tras la muerte de Caupolicán, a Don García:

\author{
Pasó de Villarrica el fértil llano \\ que tiene al sur el gran volcán vecino, \\ fragua (según afirman) de Vulcano, \\ que regoldando fuego está contino. \\ De allí volviendo por la diestra mano, \\ visitando la tierra al cabo vino \\ al ancho lago y gran desaguadero, \\ término de Valdivia y fin postrero (Canto XXXIV)
}

El autor debe referirse al volcán de Puyehue, (de ininterrumpida erupción hasta la actualidad) y al lago Ranco, más que a Osorno y el Llanquihue (por mucho más extenso que sea este lago), pues la cuenca del Valdivia es de tal categoría que transgrede la línea de cumbres con Argentina, naciendo en las inmediaciones de San Martín de los Andes.

\title{
Acertadas características térmicas de los humedales chilenos
}

Es llamativo que cuando llegue la expedición marítima de socorro al contacto con el adversario araucano se ocupe un terreno pantanoso, probablemente próximo a la costa, con el fin de guarecerse de los rigores del invierno. Nótese que la elección de un terreno pantanoso debe obedecer a las características térmicas que ofrecen estas áreas: la humedad -el agua en principio de la atmósfera, aunque también del suelo, ya en forma líquida, ya gaseosa- hace retardarse el calentamiento pero también retrasa el frío, pues libera lentamente el calor acumulado durante la 
estación cálida. Ésta bien podría ser la razón de utilizar un área pantanosa, más llana, menos fácilmente protegible que un altozano de buenas vistas, dado que tampoco el humedal ofrece protección frente a una caballería araucana totalmente incipiente, si es que ya habían comenzado a poseerla, aunque las dos últimos versos ponen el énfasis en la preparación artificial del lugar de habitación, lo que podría interpretarse como obras de avenamiento del agua sobrante, acumulada durante la estación lluviosa del invierno.

El texto lo expresa así:

Ya que todos, Señor, nos alojamos

en el húmido sitio pantanoso

y con industria y arte reparamos

la furia del invierno riguroso. (Canto XVI)

Con independencia de las características térmicas del humedal, este paraje se suele caracterizar por la acidez del suelo que condiciona la ausencia de vegetación arbórea ("por todas partes libres"), constituyendo verdaderos claros en el bosque (Sanz Donaire, XX Ciudad Real). Esta circunstancia se aprovecha para la localización del fuerte de los españoles.

Por su parte los indígenas reunidos en consejo dan por fuerte la posición tomada por los españoles con las palabras que siguen. Debe resaltarse que un militar haga una loa estratégica de la posición organizada y ponga en boca de otros semejantes los mismos argumentos que él expondría.

Que pues el sitio y puesto que han tomado

es por natura fuerte y recogido

del mar y altos peñascos rodeado,

por todas partes libre y defendido,

será de más provecho y acertado

que a su plática y trato deis oído (Canto XVI)

Incluso en el canto XX, hasta el que prosigue el relato de la batalla en torno al fuerte, el autor menciona la utilización del suelo como cama:

la regalada cama en que dormía

era la húmida tierra empantanada (Canto $\mathrm{XX}$ )

Quede aquí la duda de si el autor quería exponer el empapamiento como inconveniente añadido a las penurias que debe soportar un soldado cercado por el enemigo.

Una vez más en el canto siguiente se alude a la dificultad que los terrenos pantanosos ofrecen al avance, así como de otros valladares que oponen resistencia al tránsito. Vuelve a prevalecer, pues, una visión peyorativa de los humedales. 
También tuvimos nueva que partidos eran de Mapocho nuestros guerreros, de armas y municiones bastecidos, con mil caballos y dos mil flecheros. Más del lluvioso invierno los crecidos raudales y las ciénagas y esteros, llevándoles ganado, ropa y gente, los hacían detener forzosamente. (Canto XXI)

Las descripciones de este tipo de lugares se mantienen como también abundan los propios parajes, en los que la contienda se tiene que hacer cuerpo a cuerpo por la dificultad del terreno para la maniobra:

al pie de un cerro, a la derecha mano, cerca de una laguna y gran pantano,

donde de nuestro cuerno arremetimos un gran tropel a pie de gente armada, que con presteza al arribar les dimos espesa carga y súbita rociada; y al cieno retirados, nos metimos tras ellos, por venir espada a espada, (Canto XXII)

Como también más adelante, atrapados en el trampal, hacen uso de todas las artimañas que el terreno les brinda: obstáculo y cegamiento.

ni mano a mano dando, recibieron golpes sin descansar a manteniente como el un bando y otro, que vinieron a estar así en el cieno estrechamente que echar atrás un paso no podían, y dando apriesa, apriesa recibían.

Quien, el húmido cieno a la cintura, con dos y tres a veces peleaba; quien, por mostrar mayor desenvoltura, queriéndose mover más atascaba. Quien, probando las fuerzas y ventura, al vecino enemigo se aferraba mordiéndole y cegándole con lodo, buscando de vencer cualquier modo. (Canto XXII) 
El lodazal podía, sin embargo, ofrecer mejoras si pasaba a una mayor dilución, al predominar el agua sobre el componente terroso que la enturbiaba.



Otra vez el carácter defensivo, aunque sin explicitar la caballería

Pero lo que es lugar difícil para el combate, se convierte de reto en oportunidad para la defensa o hasta para salvar la vida:

luego que nuestro campo vio a la mira

y que a dar en la muerte iba derecho,

al vecino pantano se retira (Canto XXII)

En esto se emula lo que hacen también las fieras cuando se notan acorraladas, en busca de adarga segura:

Cual el cerdoso jabalí herido

al cenagoso estrecho retirado,

de animosos sabuesos perseguido (Canto XXII)

Pero el bravo araucano, sintiéndose seguro en este refugio, blande con más airoso modo sus armás de ataque y de defensa.

Así la tierra y cielo amenazando

en medio del pantano se presenta

y la sangrienta maza floreando,

la gente de poco ánimo amedrenta. (Canto XXII)

Hasta el punto de que la inestabilidad del terreno permite hincar, de un único mazazo, a una persona en el blando suelo:

que como clavo en húmido terreno

le sume hasta los pechos en el cieno. (Canto XXII)

\section{Lugar de ocultamiento}

A pesar de que, in extremis, un valeroso luchador quiera sacar provecho de esta posición. Esto es propio de las grandísimas capacidades humanas de adaptación, lo que probablemente coadyuve a explicar el vigor de nuestra especie, como se demuestra ya en el título de una obra recién aparecida: "El aislamiento, ¿reto u oportunidad". 
Y volviendo a una cita anterior:

Cual el cerdoso jabalí herido

al cenagoso estrecho retirado,

de animosos sabuesos perseguido (Canto XXII)

Alguien con formación literaria podría sugerir el paralelismo de los adjetivos cerdoso y cenagoso, de similar inicio y finalización (para tildarlo de figura retórica -aliteración, paranomasia-), y, por otra parte, ambos bastante apropiados al cerdo salvaje que se revuelca en la suciedad, casi epítetos. Yo prefiero una interpretación diferente, más realista: en lugar estrecho el jabalí se encuentra más seguro, defendido por paredes inmediatas, que con su empinamiento propician la inundación.

Y, para mí, a pesar de la dificultad del terreno, la abundancia de frondosa vegetación a su alrededor facilita el ocultamiento, y deviene -en la inseguridadlugar seguro.

a causa que la ciénaga era honda

y llena de espesura a la redonda. (Canto XXII)

Recuérdese, por ejemplo, que durante las invasiones vikinga e inglesa de Irlanda, los nativos también se guarecían en los tremedales interiores.

La fina apreciación del narrador vuelve, ¿inconscientemente?, a atinar a la perfección en la reseña de la realidad: una de las características de los humedales, de las ciénagas, como aquí se las denomina, es la ausencia de vegetación en ellas, lo que contrasta con la abundancia de sus márgenes, hasta el punto de hablarse en geobotánica de una orla: en España una progresiva aproximación al agua nos llevaría desde los cañaverales, a los carrizales para terminar en las espadañas ripícolas en su literalidad.

La inseguridad estratégica del lugar es algo que el cacique Rengo no duda en manifestar.

Conviene que de aquí nos retiremos

antes que en este sitio cenagoso

del enemigo puestos en aprieto,

perdamos la opinión, y él el respeto. (Canto XXII)

Como también los españoles atacantes en este lugar hubieron de ser asistidos a salir del atolladero, en el sentido literal de la palabra.

Era áspero el lugar y la salida y así seguir los nuestros no pudieron, quedando algunos dellos tan sumidos, 
que fue bien menester ser socorridos. (Canto XXII)

Otras menciones a situaciones de anegamiento son propias de las alegorías poéticas de este autor: una situación puede empeorar hasta enfangarse.

Más como suele acontecer contino, que huyendo el peligro y mal presente está en un sitio fuerte por natura de ciénagas y fosos rodeado

Una vez más al comentar las vicisitudes de Caupolicán se apela a la seguridad en el refugio de las ciénagas ante los ataques por parte de personas que desconozcan sus peculiaridades.

está en un sitio fuerte por natura

de ciénagas y fosos rodeado, donde por ser la tierra tan segura anda de solos diez acompañado, (Canto XXXIII)

\section{El humedal, suministrador de productos}

Esta realidad de humedal la corrobora por la presencia de techumbre de espadañas, una costumbre omnipresente en el mundo entero donde existen las plantas carrizosas (con gran frecuencia la cosmopolita Thypha, anea, enea, de flores conocidas como "puros" por el vulgo) que suelen crecer en las higrocoras: la barraca valenciana se cubre con la paja del arroz que se cultiva en la Albufera; en los bogs irlandeses o los fens ingleses se ha labrado la profesión de thatcher, devenido luego apellido de famosa, para la persona que construye "tejados" de paja (straw) o carrizos o cañas (reed); pero el conocido bávaro Dachau no significa, como podría aparentar en una falsa etimología inmediata "vega de techo [techar]": Dach-au, sino, procedente del alto alemán medieval, daha "légamo", lo que corrobora un nuevo papel de los humedales como suministradores de otros productos. Y a orillas del Titicaca también se utiliza la totora con el mismo fin de cubierta, como por ejemplo en Juli.

y cerca dél, cubiertas de espadañas, chozas, casillas, ranchos y cabañas. (Canto XXXIII)

4 Dachau tendría su equivalente español en Leganés, así como el estadounidense Hollywood sería La Acebeda, siempre acorde a su literalidad. 
El editor Morínigo (1983) es origen de la consideración fuertemente retocada de la obra por parte de su autor ya de vuelta a la Península y en ocasiones posteriores: sólo 1.298 versos de la Segunda Parte serían propios de la verdadera historia, de entre sus vivencias en El Arauco y por ende 3.964 testimoniales, de un conjunto de 21.160. (Morínigo: 25, 45 y 53). Los sucesivos retoques habrían ido mejorando el resultado final.

Transgredida la frontera meridional del río, la expedición, siempre adelante, ingresa en las espesuras de los bosques, en parte debido a la astucia de los taimados guías que más quieren producir en los españoles rechazo al territorio, a efecto de que vuelvan sobre sus pasos. De ahí que el pasaje se haga difícil, tanto por los peñascos como por otros valladares o impedimentos como los humedales.

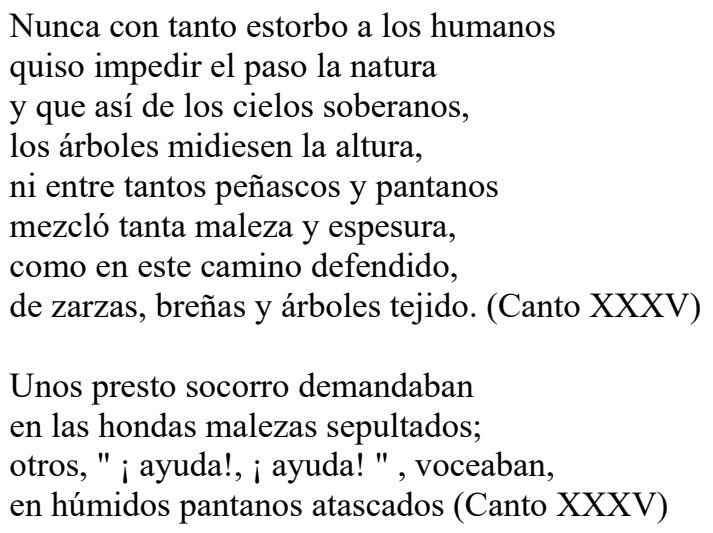

Por fin arriban a la isla de Chiloé donde se ubicará el núcleo de población de Ancud.
Al fin una mañana descubrimos de Ancud el espacioso y fértil raso, y al pie del monte y áspera ladera un estendido lago y gran ribera.
Era un ancho archipiélago, poblado de innumerables islas deleitosas (Canto XXXV)
de fina lana de vellón rizada señal de ser el clima y tierra fría (Canto XXXVI)

Más información fidedigna ofrecen los versos antepenúltimos: 
hallamos por remate y fin postrero

que el gran lago en el mar se desaguaba

por un hondo y veloz desaguadero,

que su corriente y ancha travesía

el paso por allí nos impedía. (Canto XXXVI)

Para más realidad de lo que explica graba en la corteza de un árbol -como hoy en las primeras piedras de edificios singulares, o en las cumbres de las más altas montañas-:
Aquí llegó, donde otro no ha llegado, don Alonso de Ercilla, que el primero de un pequeño barco deslastrado, con solo diez pasó el desaguadero el año de cincuenta y ocho entrado sobre mil y quinientos, por febrero, a las dos de la tarde, el postrer día, volviendo a la dejada compañía. (Canto XXXVI)

Hay un total de XXXVII cantos, siendo el último dedicado a los menesteres de Portugal y a llorar por la falta de comprensión recibida por el autor, a pesar de los muchos merecimientos.

y las honras consisten, no en tenerlas, sino en sólo arribar a merecerlas (Canto XXXVII)

\section{Un intento de explicación}

La obra de Ercilla muestra un "tono verista y la lozanía del detalle testimonial" (Waldo Rojas 1998).

Se trata de una obra per-fecta, en el sentido etimológico de la palabra, dado que se publicó inicialmente en 1569 , pero sufrió sucesivas adiciones en 1578,1589 , y 1590. Concha de Salamanca calificará el poema de "bien aderezado, bien limado y revisado" (1968: 30) y las descripciones geográficas de "verdaderas" (35). Así se expresa también C. Goić en su "La Tópica de la conclusión en Ercilla": "A diferencia de Orlando Furioso, que carece de conclusión, La Araucana, posee la conclusión más elaborada desde el punto de vista retórico que conocemos en la poesía del Renacimiento". Este perfeccionamiento debió suponer, además de la obra de un solo autor y el autor de una sola obra como repetidamente insiste Waldo Rojas en su ensayo, un preciosismo por la exposición de la verdad.

Waldo Rojas habla de la yuxtaposición en la obra de los elementos reales y "las representaciones idealizantes de personajes y de marcos naturales". En cuanto a la tratamiento de los humedales, creo poder afirmar -a la luz de las observaciones ya expuestas- que, ante la imposibilidad de revivir los paisajes coetáneos del autor, 
siendo sólo capaz de reconstruirlos en la imaginación a tenor de la visita actual a los mismos, estas notas territoriales deben ser reflejo de la realidad, más que idealización o figuración imaginativa.

Y hay numerosas citas posibles de esta misma concepción. En la obra de Medina (1916: 15) se admite: “¡Cuántas cosas aprendió en esas peregrinaciones! ¡Cuántas que parecían mentiras al referirlas y que, sin embargo, eran ciertas! [...] y si a esto se agrega que estaba dotado de un espíritu observador..." Su realismo o verismo, si queremos utilizar una palabra más genuinamente literaria, está asegurado.

En su primer viaje a Flandes como paje del entonces Príncipe Felipe (con posteridad Rey Felipe II) recorre el itinerario habitual de los españoles en estos momentos: Barcelona y por barco a Génova, luego a Milán, pasando por la llanura padana (muy probablemente Pavía), Trento, Innsbruck, Augsburgo, Bruselas 5 . Tanto en el camino como a su llegada a los Países Bajos tuvo ocasión de observar numerosos humedales. $\mathrm{Y}$ antes de su regreso, por el mismo camino aproximadamente, pues la ruta marítima directa era insegura en esos momentos, todavía visita regiones de los reinos de Bohemia y Hungría y de otros de Alemania. Inicia como acompañante real nuevo viaje, esta vez marítimo, a Inglaterra, vía La Coruña, donde tanto en las costas de la Península como en la Isla, vuelve a toparse con la realidad higrocórica. Más aún, antes de retornar a Valladolid, realiza corto viaje de nuevo a Flandes, donde conoce de las desventuras chilenas de Pedro de Valdivia. Todavía no ha empuñado la espada, sino que sigue en el servicio personal del próximo rey.

A tenor de la biografía del autor de La Araucana, tiene pues ocasión personal de contemplar -y agudeza intelectual y dotes de observación no le faltan -innumerables áreas encharcadizas centro- y sudeuropeas, sin despreciar las del Occidente isleño.

En otra ocasión Ercilla tiene que ir a recoger desde Viena a su hermana. "Él refiere en su poema que en esa ocasión "corrió» la Francia, Italia y Alemania, Silesia, Moravia, llegando hasta la ciudad de Posonia, situada a orillas del Danubio, en Pononia, y Garibay, precisando aún más los límites del viaje, dice que alcanzó hasta Neustal, "ciudad última de Austria, en la frontera de Hungría, a causa de hallarse allí por entonces los Reyes y la Corte" (Medina: 106).

Antes de escribir la segunda parte, en la que el poeta entra en escena, que es por lo tanto- la más autobiográfica, la realmente vivida- había vuelto a la metrópoli madrileña, y también se había destacado desde 1574 en viajar a través de Cartagena a Roma vía Nápoles, luego a Alemania, asiste en Bohemia (Praga) a la coronación de Rodolfo como Rey -quien luego será Emperador- y, tras recorrer Estiria y Carintia (y hasta Croacia) vuelve por Italia (Friuli) a España.

En la ida a Centroeuropa es casi seguro que haya visitado humedales en Siena, Florencia, Bolonia (en la confluencia del Reo-Po), Ferrara (Canale di Burana-Po),

\footnotetext{
${ }^{5}$ Recuérdese la famosa frase: "Cuesta más que poner una pica en Flandes".
} 
Padua, Mantua (Mincio-Po), Cremona (Adda-Po), Piacenza (Trebia-Po), Milán (entre los Lambros) y Pavía (con la Cartuja de Pavía, en plenos arrozales, obras ya medievales de bonificación de las higrocoras) ciudades todas que de modo especial recuerda en La Araucana. Ni que decir tiene que muchas de éstas, situadas en la llanura padana, son áreas todavía de importantes humedales fluviales conservados en espacios naturales, especialmente la última, en la confluencia del norteño Ticino al zonal Po. También es seguro que visitara Venecia en esta ocasión. Tras la visita a Praga pasa por Ratisbona (confluencia de los ríos Naab y Regen con el Danubio), volviendo a entrar en contacto con las mencionadas áreas encharcadas. Estas citas aparecen en la segunda parte (Canto XXVII), una vez realizados los viajes.

No puedo estar de acuerdo con lo expresado por Bernal Herrera (1991: 60) de que "se afirma que uno de los alicientes del viaje de Ercilla a América fue una decepción amorosa, sobre la cual escribió algunos versos. Había llevado hasta entonces (1555) no una vida militar sino cortesana, por lo que su abrupta decisión de irse a guerrear ha sido vista como un intento de olvidar el desengaño amoroso." Sin menospreciar la motivación última de su viaje, que el autor de estos comentarios se apresura a apostillar ("Aunque probable, lo anterior podría ser mera psicología-ficción."), lejos de esta percepción, creo que son sus experiencias -que no pueden ser sino previas- y los relatos de quienes a lo largo de sus viajes le comunicaron lo vivido en la guerra, y especialmente de los combates en las cenagosas llanuras inmediatas a Pavía, junto a la actual Cartuja, son éstas las vivencias que le llevan a una tan detallada comprensión de la naturaleza de los humedales chilenos, narrados en La Araucana.

Es llamativo que, si , como queda demostrado, en la obra original se describen -y con buen tino- los humedales y el papel que éstos desempeñan en la conquista, no aparezca ni la menor sombra de los mismos en la película que con el nombre de "La Araucana (La conquista de Chile)" se filmara en 1971. En efecto, la mencionada cinta, que expresamente admite que está basada en el poema épico de Alonso de Ercilla, presenta sólo las aventuras narradas en la Primera Parte de la obra, en la que los humedales no desempeñan papel notorio. Por el contrario, se ensalza la figura de Inés de Suárez, mujer acompañante de la expedición de Valdivia y los primeros trances del asentamiento de los españoles en Santiago del Extremo, hasta la muerte del Adelantado D. Pedro de Valdivia.

Por el contrario, la importancia de los humedales en Araucanía es tal que, más de 300 años después de compuesto el poema, un ingeniero belga destinado allí para construir los ferrocarriles menciona los lugares anegadizos en varias ocasiones, en una obra pareja a la que aquí se comenta: constituye igualmente un relato de gesta, esta vez la de doblegar la naturaleza al progreso carrilano, la incorporación del centro meridional de Chile al resto del país, a la vez que se escribe un diario de aventuras, como la misma vida en parajes remotos. En numerosas ocasiones se menciona la impracticabilidad de los caminos carreteros, las sendas, por las 
copiosas lluvias. "Estamos al fin del invierno. Hace tres meses que llueve, así que los caminos están intransitables" (Verniory 2001: 111).

En frases como "La Araucanía entra en la historia en 1861" (Verniory: 55) queda claro el relato de gesta, máxime cuando a continuación se narra la nueva intervención. A ésta se agrega de inmediato que "siguiendo al Sur de Angol, Saavedra instala nuevos fuertes en Purén y Lumaco, en una región cubierta de pantanos que en los primeros tiempos de la conquista habían servido de refugio eficaz a los indígenas frente a los intentos de la caballería española" (56). "En algunos puntos los caballos se hunden hasta el vientre y como no se sabe lo que hay bajo el barro, es arriesgado caerse" (111). Esta aseveración está explicitando la naturaleza volcánica del material que deviene en arcillas (alofán) hinchables del tipo montmorillonita, amén de esmectita, pegajosas, de tan difícil tránsito. Al hablar de las inmediaciones de Cuyanquén expone: "La tarea es muy ardua porque estamos en plena estación de las lluvias, la selva es extremadamente espesa, y se encuentran allí muchos pantanos" (151). Otro tanto se cita más adelante: "como en la estación de las lluvias sería muy molesto para los invitados llegar al fundo en la selva" junto a Lautaro (152) en un "viaje lleno de atolladeros espantosos" (253). Lo mismo se dice de la "laguna traidora" junto a Curacautín: "el caballo se hunde hasta el vientre", el jinete logra salir a duras penas de la "trampa" (322 y 323). La historia del animal incapaz de salir del trampal por sus propios medios ni de ser socorrido por los hombres que llegan en su ayuda, tendrá un final fatal. Hablando de finales azarosos también se vaticina la muerte de los malhadados que pasan sin suficiente recato ante la piedra sagrada de Retricura, junto al río Indio camino de Lonquimay, "su caballo tropezará, se lastimará o se hundirá en la ciénaga cercana" (p. 339), dado que el sendero atraviesa "vastos pantanos provenientes de la fusión de las nieves" (p. 340). La confluencia de ríos también da lugar a inmensas sábanas de agua: la unión "de los ríos Laja y Bio-Bío [...] forma una extensa napa de agua" (352). En la selva de Freire hay obstáculos como "arroyos, pantanos, en los que nuestras cabalgaduras se hunden hasta el pecho" (392) hasta alcanzar el río Toltén. Ciertos patos "retozan en medio de los llanos desnudos donde en esta estación las lluvias han formado lagunas" (452). Recuérdese que la salida al mar de este río está plagada de humedales, brazos abandonados del río, lagos yugales, el lago Queule, las marismas dulces en tránsito a albufera que cierra la flecha-restinga marina... Todo este paisaje se encuentra antes de alcanzar la población de Valdivia.

Habida cuenta que este relato se escribe 300 años después del poema de Ercilla, es notorio el papel que debieron desempeñar los humedales durante la conquista cuando tres siglos después todavía mantienen máxima actualidad.

Recopilando:

- La obra erciliana es verídica en las descripciones bien hechas, atentas a la realidad, de los humedales. 
- Como buen hijo de su tiempo, el autor mantiene una apreciación bastante peyorativa de los humedales, que sólo recientemente y por causas tecnológicas ha cambiado.

- Ni siquiera la rima, de tanta importancia en un poema, supone óbice para la exposición de la verdad-terreno.

- La obra es un documento veraz de la realidad del momento, así como punto de partida para el conocimiento de la evolución reciente del paisaje, pues la impronta natural en el mismo se ha mantenido a lo largo de la etapa colonizadora hispana e incluso en la reciente hasta nuestros días.

- El verismo literario debe su expresión a la peculiar historia del autor que, en el transcurso de su larga y azarosa vida, incluyendo los viajes, ha tenido contacto en numerosísimas ocasiones con terrenos encharcables de máxima importancia, especialmente en el norte de Italia, Alemania, Flandes, Inglaterra y Galicia, lo que añade experiencia a lo vivido en Chile.

- Dadas las dotes naturales de observación y de pesquisa e interrogatorio, debió disponer y explotar convenientemente los grandes almacenes de información albergados en origen en los coetáneos que sirvieran en las campañas militares de todos los lugares visitados.

- El autor supo asimilar esta información para dotar a su obra de frescor narrativo, cuando no epopéyico.

\section{BIBLIOGRAFÍA}

ALEGRÍA, Fernando.

1954 La poesía chilena, orígenes y desarrollo del siglo XVI al XIX. México-Buenos Aires: FCE, pp. 1-55.

ERCILLA Y ZÚÑIGA, Alonso de.

1946 La Araucana. Edc, pról. y notas de Concha de Salamanca. Madrid: Editorial Aguilar.

1983 La Araucana I y II. Edc., intr. y notas de Marcos A. Morínigo e Isaías Lerner. Madrid: Clásicos Castalia.

2005 La Araucana. Edc., intr. y notas de Isaías Lerner. Madrid: Cátedra. Álvarez Vilela, A.

1995 "La expedición a Ancud en La Araucana o la recuperación del mérito por parte de Ercilla", Anales de Literatura Hispanoamericana, $\mathrm{n}^{\mathrm{0}} 24$, pp. 77-89.

ARAYA, Guillermo.

1997 La Araucana. Estudio inicial de una selección de la obra, edición a su cargo. Santiago de Chile: Editorial Universitaria de la Universidad de Chile. 
BELLINI, Giuseppe.

2006 De Ercilla a Gaspar Pérez de Villagrá. Editorial El Cardo. En Biblioteca Virtual Universal.

http://www.biblioteca.org.ar/libros/134485.pdf

COROMINAS, J. y J. A. PASCUAL.

1991[1980] Diccionario crítico etimológico castellano e hispánico. Madrid: Gredos.

DUCAMIN, J.

1900 L'Araucana, poème épique. Morceaux choisis, précédés d'une étude biographique, bibliographique et littéraire suivis de notes grammaticales et de versification et de deux lexiques. Paris: Garnier Frères. Collection publiée sous la direction de M. E. Mérimée.

FERRER DEL RÍO, A.

1866 La Araucana de D. Alonso de Ercilla. Edc. de la Real Academia Española. Intr. de D. Antonio Ferrer del Río. Madrid: Imprenta Nacional.

GoIć, Cedomil.

1971 "La Tópica de la conclusión en Ercilla", Revista Chilena de Literatura, Universidad de Santiago de Chile, pp. 17-34.

2005 "Ercilla y Cervantes: imágenes en suspenso", Príncipe de Viana, Año $\mathrm{n}^{\circ}$ 66, $\mathrm{n}^{\circ}$ 236, (ejemplar dedicado a: Leyendo el Quijote. IV Centenario de la publicación de Don Quijote de la Mancha), pp. 651-662

GONZÁLEZ DE MENDOZA DORVIER, A.

1947 "El problema geográfico de La Araucana y la expedición de Don García Hurtado de Mendoza", Boletín de la Academia Chilena de la Historia, Santiago de Chile, XIV, nº 37, pp. 59-88.

HERRERA, Bernal.

1991 “La Araucana: conflicto y unidad”, El Criticón, no 53, pp. 57-69.

LA ARAUCANA (LA CONQUISTA DE CHILE)

1971 Película. Dir. Julio Coll, guión de Henrique Campos, Julio Coll, Enrique Llovet (y Poema de Alonso de Ercilla). Coproducción Chile-Italia-España-Perú; Lautaro Films / MGB Cinematográfica / Paraguas Films S.A. Edición de JRB Producciones, 2004.

MARTÍNEZ DE LA ROSA, F.

1827 Apéndice sobre la poesía épica española. Edc. digital en la Biblioteca Cervantes a partir de Francisco Martínez de la Rosa. Obras literarias. Paris: Imprenta de Julio Didot.

MEDINA, José Toribio.

1916 La Araucana: vida de Ercilla / de Alonso de Ercilla y Zúñiga; ilustrada con grabados, documentos, notas históricas y bibliográficas y una biografía del autor. Santiago de Chile: Imprenta 
Elzeviriana. Recogida en: Biblioteca Virtual Miguel de Cervantes, 2007.

MEJÍAS-LÓPEZ, William.

1992 “El Fitón de Alonso de Ercilla: ¿shaman araucano?", Anales de Literatura Hispanoamericana, $\mathrm{n}^{\circ}$ 21, pp. 279-195.

PÉREZ BLANCO, Lucrecio.

1993 "Presencia relevante de la descripción en La Araucana", en Poética hispanoamericana y española: relaciones. Madrid: Fundación Universitaria Española, pp. 131-169.

PERELMUTER-PÉREZ, Rosa.

1986 "El paisaje idealizado en La Araucana", Hispanic Review, vol 54, $\mathrm{n}^{\mathrm{o}} 2$, pp. $129-146$.

ROJAS, Waldo.

1997 La Araucana de Alonso de Ercilla y la fundación legendaria de Chile. Del Araucano ideal al Mapuche terreno. Alicante: Biblioteca Virtual Cervantes.

SANZ DONAIRE, J. J.

1999 "Los humedales ibércios en la Geografía de Estrabón y comentarios a la Atlántida platónica desde la óptica higrocórica", en Homenaje al Profesor José Estébanez Álvarez. Madrid: Servicio de Publicaciones de la UCM, vol I, pp. 593-605.

2000 "Descriptive and functional wetlands typology and classification", Observatorio Medioambiental, $\mathrm{n}^{\mathrm{o}}$ 3, pp. 311-339.

2001 "Los humedales en la Ilíada. Entre las cosmovisiones mediterráneas e indoeuropeas", Complutum, 12, pp. 143-162.

VEGA DE FEBLES, $\mathrm{M}^{\mathrm{a}}$.

1991 Huellas de la épica clásica y renacentista italiana en La Araucana de Ercilla. Miami: Ediciones Universal.

VERNIORY, G.

2001 Diez años en Araucanía 1889-1899. Pehuén, Santiago de Chile: Biblioteca del Bicentenario.

VIDAL GORMAZ, F.

1872 "Ercilla i el descubrimiento de Chiloé", Revista de Santiago, no I, mayo, pp. 540-545. 